\title{
Role of Community Informatics in Socio-Cultural Transformations in Russia and the CIS
}

\author{
Sergei Stafeev \\ Centre of Community Networking and Information Policy Studies (CCNS), \\ St. Petersburg, Russia < sstafeev@mail.ru >
}

\section{Preface}

The last decade is marked by the intense growth of the social sciences in Russia, expressed in the sharp increase in number of publications, and the volume of research projects, translations and periodic editions, scientific forums of different levels, and theses among others. Especially all this concerns investigations using the different interdisciplinary approaches, non-traditional research instruments and methodologies.

The evident trend toward inter-disciplinary integration in modern social investigations are clearly the "objective processes", reflecting the external and determining circumstances of modern social and cultural processes and equally resulting in the requirement for the use of non-traditional research tools, a change in the researcher's perspectives and in the approach to the interpretation of results.

The single object (the so-called "singularity" characteristic of the case-study methodology) and also the micro-level of social processes and institutions can be seen to be the focus of many recent investigations. As experience has shown, such methods allow one to work effectively in the new Russian social reality characterized by a plurality of social practices, values, lifestyles, cultures, and ways of communication.

Community Informatics (CI) —an interdisciplinary research approach linking the wide circle of specialists from the subject areas of information and communication technologies, management, social planning, social administration and some others-has just recently become known to Russian specialists.

In June 2003 within the framework of the international conference "Building the Information Commonwealth: Information Technologies and Prospects of Civil Society Development in Commonwealth of Independent States (CIS) countries"1 a series of events were held (round table, workshop, meeting of the working group) for the presentation of CI ideas and methodologies to the researchers from CIS and other participants of the Conference. The discussions were carried out by the recognized leaders of international CI, particularly Prof. Michael Gurstein, Chairman of the Global Network of CI Researchers ${ }^{2}$, Prof. Michel Menou, leading the series of research CI projects in the countries of Latin America and Prof. Wal Taylor, head of the Internet Academy, Australia.

At the same time at the conference a book entitled Community Informatics: Community Network. Prospects. Approaches. Tools. Part $1^{3}$ was presented. This book is up to the present moment is the only book in Russian reflecting the different (theoretical and practical) aspects of CI.

During the past year the different questions of "applicability" of CI theory and practice to the current social and cultural situation of CIS countries have been regularly discussed within the framework of a

\footnotetext{
${ }^{1}$ http://www.communities.org.ru/conference

${ }^{2}$ http://www.ciresearch.net

${ }^{3}$ http://ci-text.researcher.at
} 
specialized mail list, as well in non-formal discussions of the CIS participants of the CI Research Network. Here we'll try to analyze the results of these discussions and also the general problem area of applicability CI theory and practice in the CIS region.

\section{Is it possible to talk about "research in local communities" in relation to contemporary post-Soviet social reality?}

A principle position of the author of this article is to suggest that Russia is a country with a qualitatively different, compared to the Western world, set of economic and political institutions, and a country where the introduction of the neo-liberal model is manifestly following a line of borrowing the terminology, but not the real content of new social processes and institutions. This statement is based on the very considerable research undertaken in recent years, and in particular, the work of S. Kyrdina (2000).

For example, if we speak about the real content of the modern "market mechanism" of post-Soviet Russia (and also including the majority of the CIS countries) on the one hand it is possible to talk about the domination of pseudo-market forms of the relations (Nureev 2000), and on the other hand - that this name does not reflect the character of this social phenomenon (as an example, "our joint-stock companies are jointstock companies only in form"(Nureev 2000)).

Addressing the main field of the research interests of CI-the application of information and communication technologies (ICTs) at the "local" level for the purposes of local social and economic development—we should in the first place observe that for the most part current ICT projects are financed by the state (so-called e-government is largely directed to the activities and operations of the state administrative bodies).

In our previous work we have tried to show the principal dangers of such an unbalanced approach especially in the Russian context, leading as it appears to do to the further strengthening of a closed group of people (the local elite) which is often not really interested in social development or in the instrumentation of effective social policy (Stafeev 2003).

It seems appropriate to show here how different leading social researches are formulating the real purpose of the current informational and wider social policy in Russia, i.e. towards the maintenance of stability in society for the convenience of the governing elite (and therefore it is by no means concerned to address a support for socially unprotected and vulnerable groups in the general population) (Danilov 2003).

These circumstances place the researcher following CI principles in a difficult situation that requires not only professionalism and a non-standard way of thinking but also a distinctly civically oriented (and wider an ethical) position.

A high level of corruption characteristic of the majority of the post-Soviet countries, which has now been transformed into an on-going and stable system of societal relations, is widely recognized. As a rule specific "contract relations" appear to be in the process of being established between entrepreneurs and state executives and in this case the relations between State executives and entrepreneurs are often one of becoming long-term business partners (Radaev 1998).

At the local level the electoral power as a rule is gravitating toward identifying itself with local communities (Stafeev 2003), with self-government in its true and full form and at the same time with the inheritance from the Soviet day's secrecy towards information and to making decisions without consultations with local citizens or with procedures of such consultations which are very formal.

Taking all this into account it can be said that one of the main difficulties of social studies in Russia is connected to the fact that very often using the traditional "Western" terminology does not reflect the essence of the existing social processes or phenomena. 
As a most simple example of such mismatching of terminology related to the field of ICT research we can use some programs of e-government at the level of municipalities. It is possible to say that the state lends support to the institutions of self-government in order to increase their efficiency and openness but probably it would be more true to say that a big corporation - i.e. the State - informatizes its affiliation through "Municipal institution xyz Joint Stock Company".

We can, with a high degree of certainty, foresee wide use of sophisticated municipal information systems (e.g. created within the framework of the Federal Target Programs of "Electronic Russia") for personal benefit and also for enhancing inequality (of property, information and so on) at the local level".

Under such conditions the position of the social researcher as an individual citizen becomes most important: rejecting the status of courtier counselors and ideological legitimators of the existing order with the researcher in this instance taking the role of social critic interested not only in formal studies of the efficiency of this or that system, or this or that ICT project, but also trying to get outside to observe the real state of affairs. What in reality are the performed ICT projects bringing into the everyday lives of ordinary citizens, members of local community?

And here, according to the author's opinion, lies the potentially high value of using the CI approaches in our countries - and principally through the humanitarian, value-dependent direction of these studies.

An underlying but most set of criteria for upon carrying out CI research would appear to be those developed by UN Human Development Index (HDI). Without touching on details concerning the methods of the HDI design and calculation, it is important to point to the exoteric reliability and objectivity of this index including anticipated life-span, literacy of the adult population, amplitude of primary, secondary and higher education coverage, the special indicator of material well-being based on real GDP per capita and so on. Summarizing the factors of this Index, the task of all the development projects is to increase gratification of three main human needs: to live a long and healthy life, to acquire knowledge, and to have access to the resources for providing a normal standard of living.

During recent years our foreign colleagues have demonstrated a series of examples of high-level socially directed analyses, far from the standard formulations and general positivistic statements. An example might be the discussion of an "Effective Use" rather than a "Digital Divide" approach directed against superficial understanding of modern situation in the world concerning ICT use (Gurstein 2003).

\section{CI and diversity of information experience}

Unlike its "research twin" - Informatics of Organizational Systems (MIS) CI is based on the principal acceptance of the importance of non-formalizable (or formalizable with difficulty) information in undertaking studies in local communities, which in turn allows for a re-interpretation of managerial rationality using direct speech, non-formal cultural practices, non-explicit social interactions (or "voices of the subcultures").

The attention of the researcher appears to be directed not only to the research itself, to the analysis of channels of creation, consuming and transfer of information but also to investigation of specifics of using of technical means in concrete socio-cultural circumstances. In this connection, studies of the independent (and therefore mostly local) sources of information-the so-called community media-acquire very considerable significance as for example, local radio stations, community networks, local cable television etc.

It is well known that the post-industrial ("Information") society in its contemporary version develops on the basis of very serious changes in social and personal psychology. All the spheres of people's life, beginning

\footnotetext{
${ }^{4}$ See examples in

(2001). Municipal Management of Economy in the Russian federation: Results of Investigation and Recommendations. Moscow, TACIS.
} 
from the geopolitics of big national states and ending with everyday life are changing rapidly, being placed into new info-communicational realities and global networks.

It is also widely accepted that the information revolution - the Internet, communication satellites, "knowledge-based economy", has resulted in a growing inability by governments to control information flows and opportunities for everyone to get, through the Internet, access to unlimited knowledge.

There is, however, a further global process that also can be positively called the information revolution: it is radical change in the content of information flows. There is no doubt that mass media are becoming more diversified, dynamic, engrossing and entertaining. At the same time the mass media is rapidly becoming more commercialized and dependent on advertising and advertisers. At the other end of this cord are located the consumers of these information flows, urban populations, "the inhabitants of the global village."

Outside the limits of this "CNN galaxy" can be found those different groups and individuals who are being marginalized with relation to the "flows of power, resources and innovations" (in terminology of Manuel Castells): cultural minorities, communities trying to keep the traditional way of living, people without education and so on.

This divide is very rigid and overcoming this depends not only on the accessibility of technical means but also on correct policy of being able to use the new opportunities presented by ICTs, in efforts towards the creation of adequate "content".

The problem of the development of independent information sources is extremely topical for the CIS region. Such independent information systems can become the centers of real local development, sources of innovations for the development of social capital of the territory. But this requires careful investigations that might give an opportunity to suggest the appropriate strategy and tactics for the support and realization of such projects.

\section{CI and State Informational Policy}

While reasoning about the limits of CI applicability in the post-Soviet space, it seems necessary to ask the question about the practical use of CI results and in particular about their use for influencing and "correcting" the results of state policy in the field of informatisation.

One of the most probable areas would be in using a CI methodology for "interactive monitoring" of State ICT programs. Historically in Russia large-scale state programs (the Federal target Program "Electronic Russia" is an example) have never had mechanisms or actors for monitoring their performance or output. That is why, for example, there is so little flexibility or "reflexivity" (responsiveness) in such programs.

It often happens that some program elements are found to be defective or simply unneeded, but there is nobody in a position to provide a systematic monitoring and feedback on these programs to make this known at the level of execution.

Understanding of this circumstance might help the authorities to see in CI a highly effective methodology of alternative (independent) "interactive monitoring" capable of fixing, measuring and analyzing the technological and socio-cultural factors which appear in the course of ICT programs realization and which usually stay outside the "attention focus" of the specialists responsible for results estimation within the program itself.

Such a role requires not only constant reflection towards analytical prescriptions supportive of multiparadigmatic and interdisciplinary approaches, but also collaboration with civil society institutions which are themselves capable not only of impartially criticizing state policy but also of developing strategies and methods for constructive cooperation. 


\section{References Cited}

(2001). Municipal Management of Economy in the Russian federation: Results of Investigation and Recommendations. Moscow, TACIS.

Danilov, F. N. (2003). "Globalism, Regionalism and Modern Processes of Transformation." Sociological Investigations 4.

Gurstein, M. (2003). "Effective Use: A Community Informatics Strategy Beyond the Digital Divide." First Monday 8(12).

Kyrdina, S. G. (2000). Institutional Matrixes and the Development of Russia. Moscow, TEИС.

Nureev, R. M. (2000). Transformation of Economical Institutions in Post-Soviet Russia. Moscow, MONF.

Radaev, V. V. (1998). Formation of New Russian Markets: Transaction Charges, Forms of Control and Business Ethics. Moscow, Center of Political Technologies.

Stafeev, S. (2003). Community informatics in Russia. Community Networking and Community Informatics. M. Gurstein, M. Menou and S. Stafeev, CCNS.

Stafeev, S. (2003). Informational Policy of Russia: View from the Side of Civil Society. Geneva, UNECE. 